\title{
Chemical treatment for the sodium hydroxide \& epoxy resin for produce sugar cane bagasse fibre pulp rein forced epoxy composites material
}

\begin{abstract}
Waste recycling has been the main topic of various scientific researches due to environmental management. Renewable agricultural sources such as pineapple leaf, sisal and sugarcane bagasse are among agro waste, normally known as biomass which is recently used for reinforcing polymeric materials. Sugarcane bagasse fibre residues have been extensively investigated and employed as a source of reinforcement of polymers. In the present research work a sugar cane bagasse fibre reinforced epoxy composite material has been developed with $35 \%, 45 \%, 55 \%$ of sugar cane bagasse fibre pulp with $50 \%, 40 \%$ and $30 \%$ mixed in epoxy resin. Experimental work was done to study the composite sheet of the thickness, density, impact strength and tensile strength properties. According to the analysis, it has observed that all the parameters are significantly affected. The overall results indicate the has fact that the highest tensile strength of composite sheet having a composition of $35 \%$ fibre pulp and $50 \%$ epoxy resin and higher impact strength composite sheet having a composition of $55 \%$ pulp ratio and $30 \%$ epoxy resin. The natural sugar cane bagasse fibre epoxy resin composite can lead to green manufacturing and can be used for a sustainable green environment. The major residue is normally burnt for energy supply in the sugar and alcohol industries and as a result, tons of ash is created. This create sever environmental problem like air pollution, smoke formation.
\end{abstract}

Keywords: sugarcane bagasse fiber pulp, epoxy, hardener, tensile strength, impact strength
Volume 6 Issue I - 2020

\author{
Ramratan,' Rohit Kumar ${ }^{2}$ \\ 'Assistant Professor, Giani Zail Singh Campus College of \\ Engineering and Technology, Maharaja Ranjit Singh Punjab \\ Technical University, India \\ ${ }^{2}$ Research Scholar, Department of Textile Engineering, Giani Zail \\ Singh Campus College of Engineering and Technology, Maharaja \\ Ranjit Singh Punjab Technical University, India
}

Correspondence: Ramratan,Assistant Professor, Giani Zail Singh Campus College of Engineering and Technology, Maharaja Ranjit Singh Punjab Technical University, Bathinda-15I00I, Punjab, India,

Email ramrata333@gmail.com, rohitkum6858@gmail.com

Received: February 04, 2020 | Published: February 17, 2020
Abbreviations: EFBs, empty fruit bunches; CSRP, coir and sisal reinforced polyester composite; CJRP, coir and jute reinforced polyester composite; JSRP, jute and sisal reinforced polyester composite

\section{Introduction}

Sugarcane is an important crop for sugar world Wide. The good example of this is sugarcane bagasse fiber pulp which are either burned in the field or thrown out. This creates sever environmental problem like air pollution. ${ }^{1-3}$ The increasing greenhouse gas emissions and global warming during climate change results in the increased frequency and intensity of extreme weather event. Climate change is expected to have important consequences for sugarcane production in the world. Sugarcane production may have been negatively affected and will continues to be considerably affected by increases in the frequency and intensity of extreme environmental conditions due to climate change. ${ }^{4-6}$ The bio waste has become interesting materials to be used as reinforcement in polymer matrix to develop green composites because there is biodegradable, less expensive, light weight, easy processing high specific modulus and also environmentally appeal. The interest in long term sustainability of material resources has make advancement. In bio composites or polymer composites material which made from natural fibers and resin. ${ }^{7,8}$ Plant fibers from agricultural crops are renewable materials which have potential for creating green products and replacing synthetic materials which have potential for creating composite sheet. ${ }^{9,10}$
The carried out a research work in the field of sisal fibre reinforced polymer composites with special reference to the structure and properties of sisal fibre, processing techniques, and the physical and mechanical properties. Thus, it can be concluded that with systematic and persistent research there will be a good scope and better future for sisal fibre polymer composites in the coming years. ${ }^{11}$ The studied about Sisal/Glass fibre hybrid composites and the compressive and impact properties of these hybrid composites. It is observed that the compressive and impact strength of sisal/glass fibre hybrid component is higher than sisal fibre reinforced composite, but lower than the glass reinforced composite. ${ }^{12}$ Prepared hybrid composites of unsaturated polyester based sisal/glass fibre hybrid composites. The sisal is a natural fibre which is also biodegradable and glass fibre is a synthetic fibre. It is observed that the thermal conductivity of sisal/glass fibre hybrid component is higher than sisal fibre reinforced composite, but lower than the glass fibre reinforced composite. ${ }^{13}$ The evaluated experimentally the effect of hybridization on Mechanical properties on coir and sisal reinforced polyester composite (CSRP), coir and jute reinforced polyester composite (CJRP), jute and sisal reinforced polyester composite (JSRP). It has been studied that the tensile properties of natural fibre composites can be significantly improved by natural fibres in a sandwich construction. This work also demonstrates the potential of this hybrid natural fibre composite materials for use in a number of consumable goods. ${ }^{14}$ The developed sisal fibre and its composites. The properties of sisal fibre itself interface between sisal fibre and matrix, properties of sisal-fibre in forced composites and their hybrid composites have been reviewed. It is observed Sisal and 
glass fibres can be combined to produce hybrid composites which take full advantage of the best properties of the constituents. Almost all the mechanical properties show 'positive' hybrid effects. ${ }^{15}$

The aim of this study is utilized agricultural waste which may be profitable, pollution free and economically viable for the farmer and industries. These composites are also used in panel for partition and false ceiling, wall sheet, floor, window and door frame.

This present research works a sugar cane bagasse fibre reinforced epoxy composite material sheet has been utilised with $35 \%, 45 \%$, $55 \%$. But previous literature view studies according to be utilised sugar cane bagasse fibre composite sheet $20 \%$ to $30 \%$. Application of high-performance composites using natural fibers is increasing in various engineering field. Composite material comprising one or more phase belonging to natural or biological origin. The composites produced today with the incorporation of natural fiber as rein forcements. In epoxy matrix are used for boat hulls, surfboards, sporting goods, building panel this not only reduces the cost but also save from environmental pollution.

\section{Material and methods}

\section{Material}

Raw material: Sugarcane leaves were collected from a local sugar mill. The sugarcane bagasse fiber contains many impurities like dust, dirt and foreign matter therefore it needs to be cleaned. In order to get pure sugarcane baggage fiber. After cleaning with water. The sugarcane was dried directly under the sun light for 1 day after dry sugarcane bagasse fiber, after sugarcane bagasse fiber is dip under sodium hydroxide 1 to 2 day; put $1 \mathrm{~kg}$ fiber in the cooking pot. Make a solution of sodium hydroxide pour the solution in the pot with sugarcane fiber and boil for 2 to 3 hour, after that, it will become pulp and we will wait for it to cool down and wash him with water three to four time, after that we will blend with the help of blending machine and then we will are squeeze with help of cotton fabric.

Reinforcement: The purpose of the reinforcement in a composite material is to increase the mechanical properties of the neat resin system. All of the different fibers used in composites have different properties and so affect the properties of the composite in different ways. For most of the applications, the fibers need to be arranged into some form of sheet, known as a fabric, to make handling possible.

Natural fiber composites: Natural fiber composites are made of Cotton, Flax, Jute, Sisal, Hemp and non-conventional fiber such as coir \& different EFBs (empty fruit bunches) and wood fibers. Wood fiber thermoplastic composites are attractive, insect- and rot-resistant, and paintable that can be made to have the look of wood. In addition, they are stiffer, cheaper than plastic products, with more life-cycle case, Vegetable fiber thermoplastic composites are attractive to the automotive industry because of their low density and ecological advantages over conventional composites natural fibres are lingo cellulosic in nature. These composites are gaining importance due to their non-carcinogenic and bio-degradable nature.

The natural fiber composites can be very cost-effective material especially for building and construction industry (panels, false ceilings, boards etc.) packaging, automobile and railway coach interiors and storage devices. This also can be a potential candidate in making of composites, especially for partial replacement of high cost glass fibers for low load bearing applications. However, in many instances residues from traditional crops such as rice husk or sugarcane bagasse or from the usual processing operations of timber industries do not meet the requisites of being long fibers.

Large varieties of sugar cane grow abundantly in many parts of India. Cane is crushed in a series of mills each consisting of at least three heavy rollers. Due to the crushing, the cane stalk will break in small pieces and subsequent milling will squeeze the juice out. The juice is collected and processed for production of sugar. The resulting crushed and squeezed cane stalk, named bagasse, is considered to be a by-product of the milling process. Bagasse is essentially a waste product that causes mills to incur additional disposal costs. Bagasse is a fibrous residue that remains after crushing the stalks and contains short fibers. It consists of water, fibers and small amounts of soluble solids. Percent contribution of each of these components varies according to the variety, maturity, method of harvesting and the efficiency of the crushing plant.

Preparation of composites sheet: After that, the polyester Resin and hardener mixed in a container and Stirred well for 3 to 5 minutes. The sugarcane fiber was then added gradually and stirred to allow proper dispersion of fiber within the gel like mixture. Before the mixtures were poured inside the mould, the mould was initially polished with a release agent to prevent the composites from sticking to the mould upon removal. Finally, after the mixture had been poured into the mould, it was left at sunlight for 3 to 5 day. For fully cured and hardened.

Hardener: To convert epoxy resin to epoxy plastic a reaction take place with a suitable substance called hardener (Table 1).

Table I The chemical composition of sugarcane bagasse

\begin{tabular}{lll}
\hline S. no & Component (\%) & Chemical composition (\%) \\
\hline 1 & Cellulose & 42 \\
2 & Hemicellulose & 25 \\
3 & Lignin & 20 \\
4 & Ashe & 4
\end{tabular}

Reason to choose sugarcane bagasse fiber: The sugarcane bagasse fiber which is either burned in the sugar industry, alcohol industries and as a result, tons of ash is created. This create sever environmental problem like air pollution, smoke formation and increasing greenhouse gas emissions and global warming during climate change. The main aim chose sugarcane bagasse fiber utilize of agricultural waste which may be profitable, pollution free and economically viable for the farmer and industries (Table 2).

Table 2 Specimen composition

\begin{tabular}{lllll}
\hline S. no & $\begin{array}{l}\text { Fiber ratio } \\
(\%)\end{array}$ & $\begin{array}{l}\text { Thickness } \\
(\mathbf{m m})\end{array}$ & $\begin{array}{l}\text { Epoxy } \\
(\%)\end{array}$ & $\begin{array}{l}\text { Hardener } \\
(\%)\end{array}$ \\
\hline 1 & 35 & 4 & 50 & 15 \\
2 & 45 & 4 & 40 & 15 \\
3 & 55 & 4 & 30 & 15 \\
4 & 35 & 8 & 50 & 15 \\
5 & 45 & 8 & 40 & 15 \\
6 & 55 & 8 & 30 & 15 \\
\hline
\end{tabular}




\section{Methods}

Mechanical characteristics of composites sheet.

Thickness testing: For measuring the thickness of a wire or a plate, calipers micrometer is used. Principal of the measurement of sheet thickness, the sample is kept between two plane parallel plate and a known arbitrary pressure is applied between the plates than the distance between the plates is measured precisely (Figure 1).

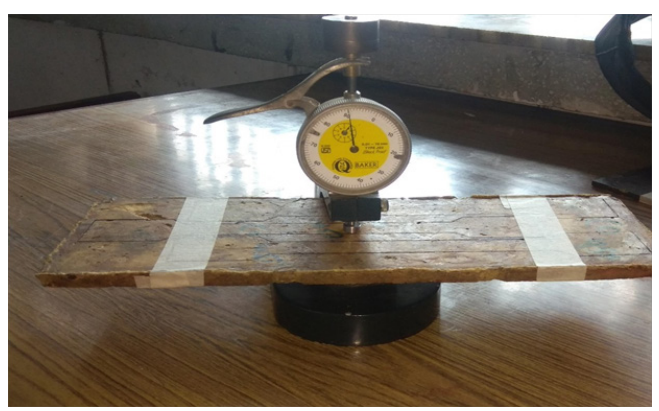

Figure I Thickness testing instruments.

Tensile strength test: Tensile strength is the ability of material to resist the forces that pulls it apart or it is the resistance of material to breakage under tension. The tensile test was performed as per ASTMD- 638 standards. For tensile testing the Specimen was cut as per the dimensions, detailed dimensions for this are shown in Figures $2-4$.

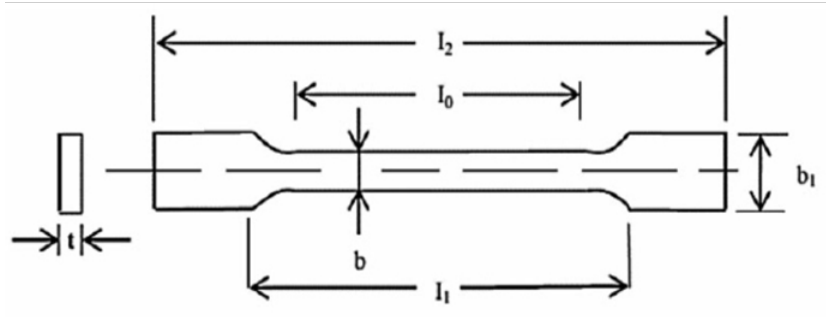

Figure 2 Tensile specimen dimension.
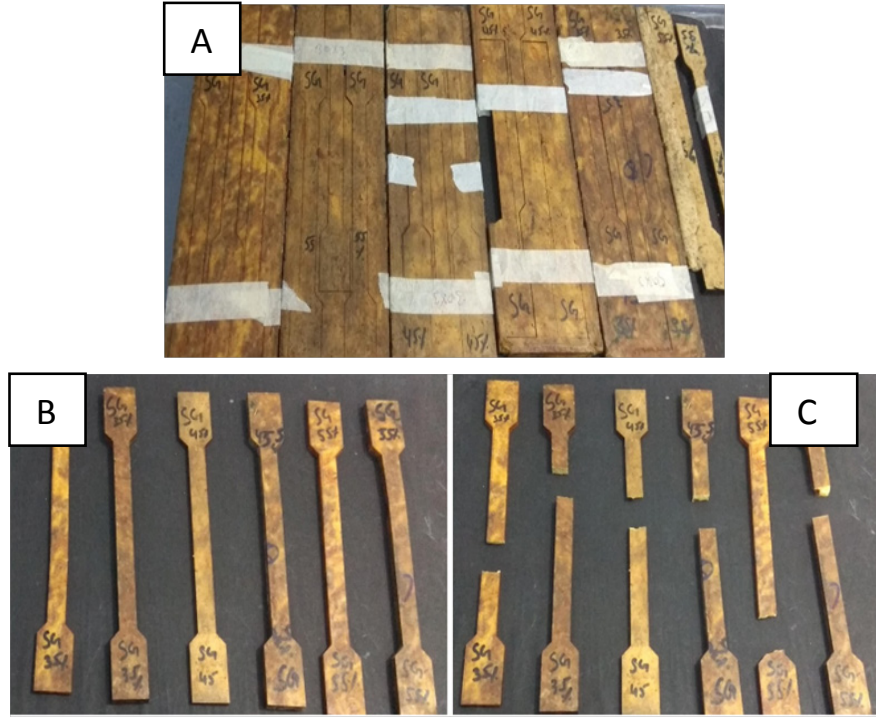

Figure 3 A Sample of the composite sheet, B: Tensile specimen, C: Broken specimen testing specimen after tensile testing.

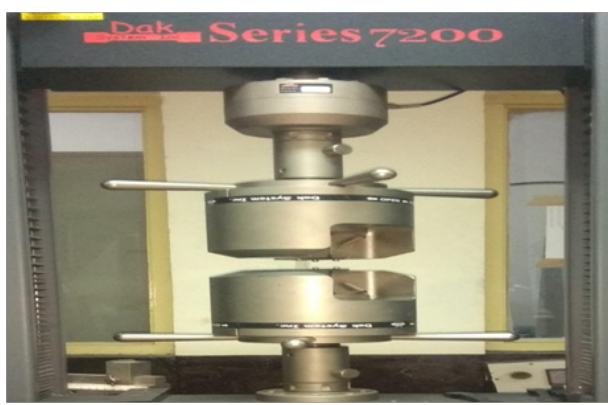

Figure 4 Tensile strength Instruments.

Impact strength test: Impact strength is the ability of a material to absorb impact energy without breaking. Impact test are performed to know the toughness of material. The specimen was subjected to a large amount of force for a small interval of time. A material with more impact energy will have more toughness. For impact strength testing the Specimen was cut as per the dimensions, detailed dimensions for this are shown in Figures 5-7.

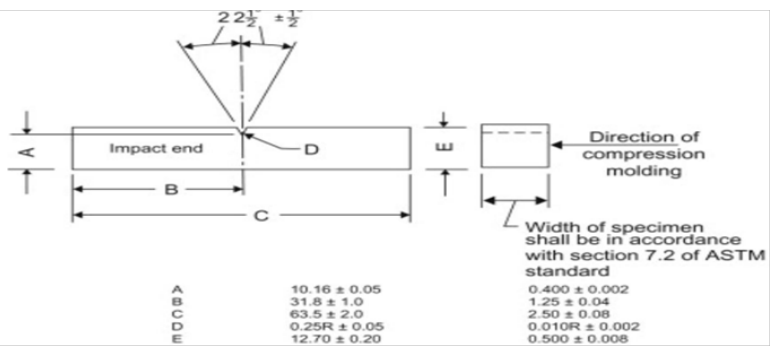

Figure 5 Dimension specification of the impact strength equipment.

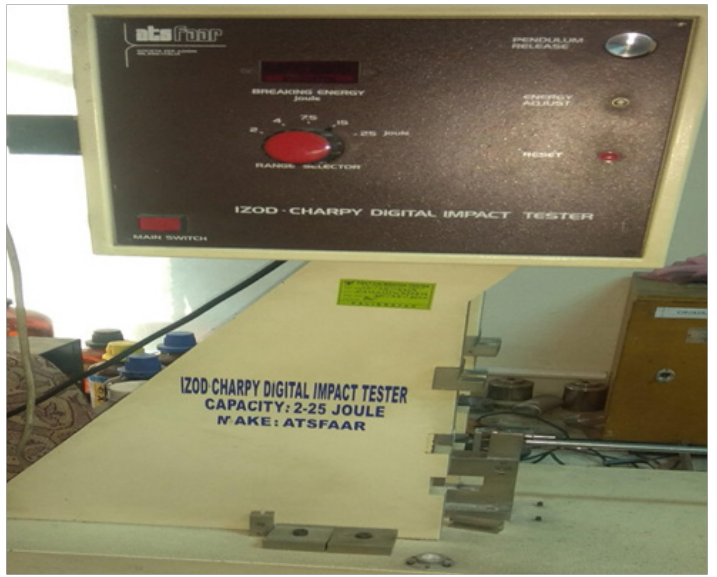

Figure 6 Impact strength instruments.

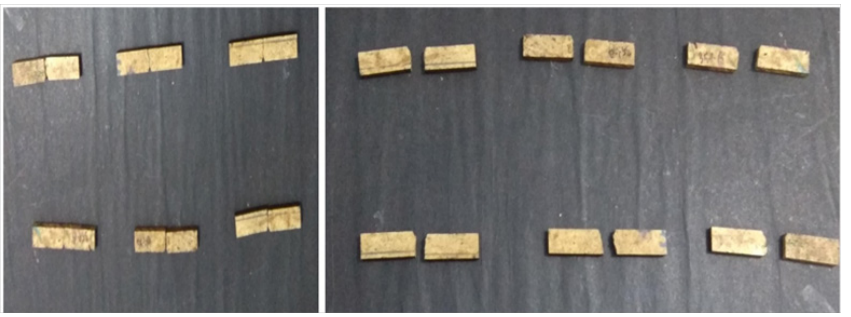

Figure 7 A Impact specimen, B: Broken specimen after impact strength testing. 


\section{Results and discussions}

\section{Density of the composite sheet}

a. The Density testing was done on six composites sheet and the results are noted in form of the Tables 3-9.

b. As we can see that as fiber to resin ratio, when the percentage of fiber is decreased, we have increase in density of composite. c. But as the density increases results in increases of hardness of plate as measured above

d. As per shows in Figure 8 analysis of composite sheet of density module of composites.

e. The increase in fiber percent gives higher density as analyzed by the graph.

Table 3 Sheet thickness test

\begin{tabular}{lllll}
\hline S. no & Fiber ratio (\%) & Various thickness & Mean & Thickness $(\mathbf{m m})$ \\
\hline 1 & 35 & $4.12,4.23,4.42,4.54,4.62,4.22,4.66,4.90,5.12,4.96$ & $45.79 / 10$ & 4.579 \\
2 & 45 & $4.35,4.54,4.65,4.78,4.86,4.64,4.33,5.07,5.24,4.87$ & $47.33 / 10$ & 4.733 \\
3 & 55 & $4.66,4.75,4.85,4.20,4.32,4.35,4.38,4.42,4.58,4.85$ & $45.36 / 10$ & 4.536 \\
4 & 35 & $7.80,7.98,8.08,8.21,8.23,8.56,8.76,8.84,8.11,8.81$ & $83.38 / 10$ & 8.338 \\
5 & 45 & $8.12,8.54,8.32,8.56,8.00,8.41,8.28,8.21,8.46,7.98$ & $82.88 / 10$ & 8.288 \\
6 & 55 & $8.24,8.42,8.57,8.86,8.56,9.22,9.55,9.78,9.37,9.24$ & $89.81 / 10$ & 8.981 \\
\hline
\end{tabular}

Table 4 Sample GSM

\begin{tabular}{lllll}
\hline S. no & Thickness $(\mathbf{m m})$ & Ratio $(\%)$ & Weight $(\mathbf{G m})$ & Gsm $\left(\mathrm{g} / \mathrm{m}^{2}\right)$ \\
\hline 1 & 4 & 35 & 143 & $143 \mathrm{gm} / 0.03=4766.66$ \\
2 & 4 & 45 & 136 & $136 \mathrm{gm} / 0.03=4533.33$ \\
3 & 4 & 55 & 129 & $129 \mathrm{gm} / 0.03=4300$ \\
4 & 8 & 35 & 254 & $254 \mathrm{gm} / 0.03=8466.66$ \\
5 & 8 & 45 & 252 & $252 \mathrm{gm} / 0.03=8400$ \\
6 & 8 & 55 & 243 & $243 \mathrm{gm} / 0.03=8100$ \\
\hline
\end{tabular}

Table 5 Sample density

\begin{tabular}{llll}
\hline S. no & Ratio $(\%)$ & Thickness $(\mathbf{m m})$ & Density $\left(\mathrm{g} / \mathrm{m}^{3}\right)$ \\
\hline 1 & 35 & 4 & $143 \mathrm{gm} / 120=1.191$ \\
2 & 45 & 4 & $136 \mathrm{gm} / 120=1.1333$ \\
3 & 55 & 4 & $129 \mathrm{gm} / 120=1.075$ \\
4 & 35 & 8 & $254 \mathrm{gm} / 240=1.0583$ \\
5 & 45 & 8 & $252 \mathrm{gm} / 240=1.05$ \\
6 & 55 & 8 & $243 \mathrm{gm} / 240=1.0125$ \\
\hline
\end{tabular}

Table 6 Specimen dimension

\begin{tabular}{llll}
\hline S. no & Symbol & Description & Dimension $(\mathbf{m m})$ \\
\hline I & 10 & Gauge length & 145 \\
2 & II & Grip distance & 160 \\
3 & 12 & Overall length & 240 \\
4 & b & Width of narrow parallel portion & 15 \\
5 & bI & Width ends & 30 \\
6 & T & Thickness & 4,8 \\
\hline
\end{tabular}


Table 7 Tensile strength result

\begin{tabular}{llllll}
\hline S. no & Fiber ratio (\%) & Thickness $(\mathbf{m m})$ & $\begin{array}{l}\text { Tensile strength I } \\
(\text { Mpa) ASTMD - 638 }\end{array}$ & $\begin{array}{l}\text { Tensile strength 2 } \\
(\text { Mpa) ASTMD - 638 }\end{array}$ & Mean tensile strength \\
\hline 1 & 35 & 4 & 4.35 & 4.1 & 4.225 \\
2 & 45 & 4 & 3.16 & 4.1 & 3.63 \\
3 & 55 & 4 & 2.75 & 3.02 & 2.885 \\
4 & 35 & 8 & 8.12 & 7.35 & 7.75 \\
5 & 45 & 8 & 6.76 & 3.4 & 5.08 \\
6 & 55 & 8 & 4.12 & 3.96 & 4.04 \\
\hline
\end{tabular}

Table 8 Impact specimen dimension

\begin{tabular}{lll}
\hline S. no & Description & Dimension $(\mathbf{m m})$ \\
\hline 1 & Length of specimen & 63.5 \\
2 & Centering of notch & 2.54 \\
3 & Radius OS notch type $v$ & 0.25 \\
4 & Angle of notch & $45^{\circ}$ \\
5 & Width & 12.7 \\
6 & Thickness & 4,8 \\
\hline
\end{tabular}

Table 9 Impact strength result

\begin{tabular}{llllll}
\hline S. no & Fiber ratio $(\%)$ & Thickness $(\mathbf{m m})$ & $\begin{array}{l}\text { Impact strength I } \\
\left(\mathbf{K j} / \mathbf{m}^{2}\right) \text { ASTMD }-256\end{array}$ & $\begin{array}{l}\text { Impact strength 2 }(\mathbf{K j} / \\
\left.\mathbf{m}^{2}\right) \text { ASTMD - 256 }\end{array}$ & Mean impact strength \\
\hline 1 & 35 & 4 & 1.1 & 1.22 & 1.16 \\
2 & 45 & 4 & 1.68 & 1.33 & 1.505 \\
3 & 55 & 4 & 2.04 & 1.79 & 1.915 \\
4 & 35 & 8 & 1.98 & 2.64 & 2.31 \\
5 & 45 & 8 & 2.11 & 2.13 & 2.12 \\
6 & 55 & 8 & 2.06 & 2.98 & 2.52 \\
\hline
\end{tabular}

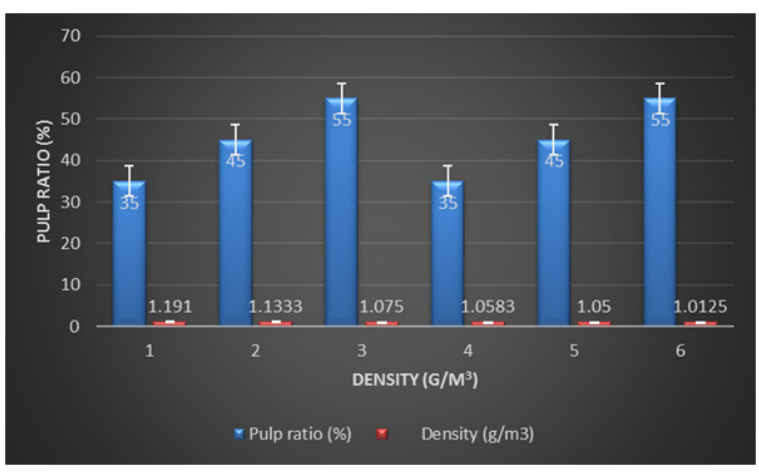

Figure 8 Pulp ratio and density of the composites sheet.

\section{Tensile strength of the composite sheet}

Six different type of composite sample are tested in dark series
7200 machine name universal testing machine. Sample is lift to break till the ultimate strength occurs. The Table 7 shows the variations in tensile strength of different sample.

i. As we can see the above table readings the tensile testing, the results up to $35 \%$ pulp and $50 \%$ composition the reading is highest

ii. As per show the below Figure 9, it clearly analyzes the data which lead to highest tensile strength of composite sheet having composition of $35 \%$ fiber and $50 \%$ resin.

\section{Impact strength of the composite sheet}

The impact strength testing was done on six composite sheets and the result is noted in form of Table 9. As per show the variation in impact strength of different samples.

A. As we see that as pulp to resin ratio, when the percentage of fiber is increasing, we have increase in impact strength of composite 
B. In order to find the impact capability of sample impact test is carried out using Izod-Charpy digital impact testing machine. Absorbed energy obtained for six different composite samples from the impact machine show in Figure 10.

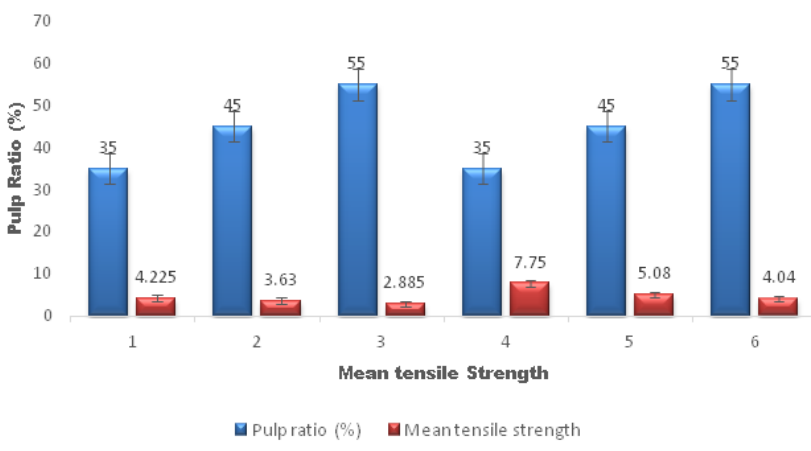

Figure 9 Pulp ratios and mean tensile strength.

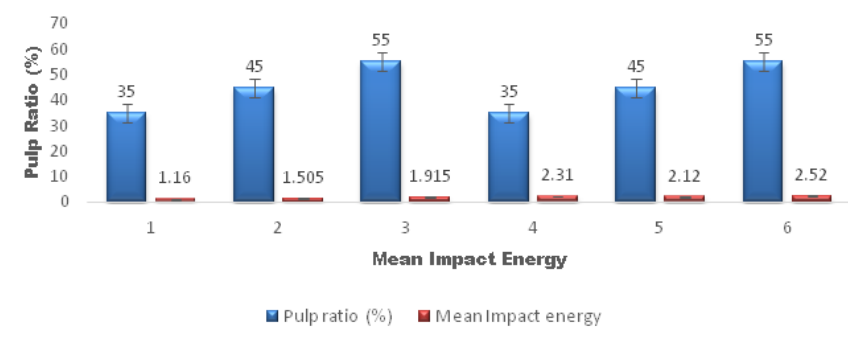

Figure 10 Pulp ratio and mean impact energy.

\section{Conclusion}

This study involves mechanical characterization of properties of sugar cane bagasse resin composites. Experimental and analytical observation of pulp ratio and epoxy resin composite leads to following conclusions:

a. The tensile strength of Fiber pulp epoxy resin composite improves by increasing fiber percentage initially $35 \%$ to $55 \%$ fiber pulp, addition of $55 \%$ pulp in tensile strength less the best properties were found for composite containing 35\% fiber and $50 \%$ resin solution.

b. The impact strength of composite improves by adding the fiber to it.

c. As last, the natural fiber pulp epoxy resin composite can lead to green manufacturing and can be used for sustainable green environment, which has strength to replace conventional materials.

\section{Acknowledgments}

The Authors wishes to express their heartfelt gratitude to the authorities of GZSCCET bathinda to provide the facilities for conducting the required test in their laboratories. Special thanks are also due to the HOD and staff of Textile Engineering Department of Giani Zail Singh Campus College of engineering and technology, Maharaja Ranjit Singh Punjab Technical University, Bathinda 151001, Punjab (India), without whose help this work would not have been.

\section{Funding}

None.

\section{Conflicts of interest}

Authors have declared no conflicts of interest.

\section{References}

1. Agarwal BD, Broutman LJ. Analysis and performance of fiber composites. New York: John Wiley \& Sons; 1980;2(1):3-12.

2. Chand N, Rohatgi PK. Natural fibers and their composite. Delhi: Periodical Experts; 1994.

3. Rajeev J, Anil K Rajvanshi. Sugarcane leaf-bagasse gasifiers industrial heating applications. Biomass and Bioenergy. 1997;13(3):141-146.

4. David F, Anne W. Biomass briquettes and pellets. Ashden; 2013.

5. Chandel AK, Silvi S da Silva. Walter C, et al. Sugarcane bagasse and leaves, foreseeable biomass of biofuel and bio products. Chem Technol Biotechnol Journal. 2011;25(5):1-9.

6. Chesta T. Producing fuel briquettes from sugarcane waste. EWBUK national research \& education conference our global future. 2011;2(1):9-44.

7. Bonelli PR, Ramos ME, Cukierman AL. Potentialities of the brochure generated from raw and acid pre-treated sugarcane agricultural wastes. Asia Pacific International Symposium on Combustion and Energy Utilization; 2006.

8. Michael Saska, Matthew Gray. Pre-treatment of sugarcane leaves and bagasse pith with lime-impregnation and steam explosion for enzymatic conversion to fermentable sugars. 28th Symposium on Biotechnology for Fuels and Chemicals Nashville; 2006.

9. Luz SM, Goncalves AR, Delarco AP. Mechanical behaviour and microstructural analysis of sugarcane bagasse fibres reinforced polypropylene composites. Brazil: Universiade de Sao Paolo; 2007.

10. De Sousa MV, Monteiro SN. Evaluation of pre-treatment size and molding pressure on flexural mechanical behavior of chopped bagasse polyester composites. 2003 .

11. Joseph K, Romildo Dias TF, James B, et al. A Review on sisal fibre reinforced polymer composites. $R$ Bras Eng Agric Ambiental. 1999;3(3):367-379.

12. Prasad Naidu VN, Ramachandra R, Ashok KM, et al. Compressive \& impact properties of sisal fiber reinforced hybrid composites. International Journal of Fiber and Textile Research. 2011;1(1):11-14.

13. Prasad Naidu VN, Rama Chandra G, Ashok Kumar M. Thermal conductivity of sisal-glass fibre reinforced hybrid composites. International Journal of Fiber and Textile Research. 2011;1(1):28-30.

14. Dixit S, Verma P. The effect of hybridization on mechanical behavior of coir-sisal -jute fibres reinforced polyester composite material. Research Journal of Chemical Sciences. 2012;2(6):91-93.

15. Yan Li, Mai YW, Lin Ye. Sisal fibre and its composites. A review of recent developments. Composites Science and Technology. 2000;60(2):20372055 . 